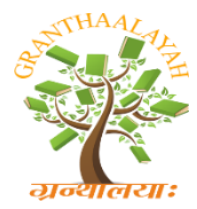

$$
\begin{gathered}
\text { INTERNATIONAL JOURNAL OF RESEARCH - } \\
\text { GRANTHAALAYAH } \\
\text { A knowledge Repository }
\end{gathered}
$$

Science

\title{
DETERMINATION OF ADSORPTION KINETICS OF COCONUT HUSK ADSORBENT FOR HEAVY METALS REMOVAL USING LANGMUIR AND FREUNDLICH ISOTHERM EXPRESSIONS
}

\author{
Sirajo L. ${ }^{1}$, Musa L. ${ }^{* 2}$, Ndanusa I. A. ${ }^{3}$ \\ ${ }^{1,2,3}$ Department of Chemical Engineering, Kaduna Polytechnic, Kaduna, Nigeria
}

\begin{abstract}
Adsorption of heavy metal cationic ions $(\mathrm{Cr}, \mathrm{Pb}$, and $\mathrm{Cu}$ ) onto coconut husk carbon $(\mathrm{CHC})$ adsorbent has been studied using batch-adsorption method. The study was carried out to investigate the adsorption kinetic and adsorption isotherm of the coconut husk adsorbent for the removal of heavy metals in waste liquid effluent. The influence of $\mathrm{pH}$, contact time, adsorbent dose, and adsorbent concentration, and temperature on the adsorption process was also studied. Results indicated an initial increase in adsorption rate, and optimal removal of heavy metal was reached within 70 minutes, further increase in contact time and temperature show significant change in equilibrium concentration. Also, further increase in adsorbent dosage revealed significant change in the sorption capacity of the CHC. The adsorption isotherms could be fitted well by both Langmuir and Freundlich models. The RI (equilibrium parameter) value in the present investigation was less than 1 (one) which indicates that the adsorption of the heavy metals ions on the $\mathrm{CHC}$ is favorable. The value of $\mathrm{n}$ for this study which indicates the degree of non-linearity between solution concentration and adsorption were $0.31-0.39$, this result indicated that the adsorption of heavy metals onto the $\mathrm{CHC}$ is a chemical sorption. After treatment of synthetic heavy metal solution with the $\mathrm{CHC}$, the adsorption isotherm model analysis revealed that the adsorption capacity (b) of CHC for the heavy metal were $89 \mathrm{mg} / \mathrm{L}(\mathrm{Cr}), 125.5 \mathrm{mg} / \mathrm{L}(\mathrm{Pb})$, and $129.7 \mathrm{mg} / \mathrm{L}$ $(\mathrm{Cu})$. Conclusively, the results indicate that the freely abundant agricultural waste-coconut husk can be treated for heavy metal adsorption but it's not economically viable because it's not renewable due to the chemisorption nature of the adsorption process.
\end{abstract}

Keywords: Langmuir; Freundlich; Equilibrium; Effluent; and Coconut husk.

Cite This Article: Sirajo L., Musa L., and Ndanusa I. A.. (2018). "DETERMINATION OF ADSORPTION KINETICS OF COCONUT HUSK ADSORBENT FOR HEAVY METALS REMOVAL USING LANGMUIR AND FREUNDLICH ISOTHERM EXPRESSIONS." International Journal of Research - Granthaalayah, 6(10), 87-94. https://doi.org/10.29121/granthaalayah.v6.i10.2018.1165. 


\section{Introduction}

Activated carbon can be derived from many different sources and produced in varying production processes. The raw materials used, activation process, and process parameters determine the physical properties and performance characteristics of the resulting carbon. Modifying these activation properties determines the porosity and pore volume distribution in the carbon. The present study has been undertaken to studies Langmuir and Freundlich isotherm for the adsorption of heavy metal ions $(\mathrm{Cr}, \mathrm{Pb}$, and $\mathrm{Cu})$ onto coconut husk.

Activated carbon is defined as a carbonaceous material with a large internal surface area and highly developed porous structure resulting from the processing of raw materials under high temperature reactions. It is composed of $87 \%$ to $97 \%$ carbon but also contains other elements depending on the processing method used and raw material it is derived from. Activated carbon's porous structure allows it to adsorb materials from the liquid and gas phase. Its pore volume typically ranges from 0.20 to $0.60 \mathrm{~cm}^{3} / \mathrm{g}$, and has been found to be as large as $1 \mathrm{~cm}^{3} / \mathrm{g}$. Its surface area ranges typically from 800 to $1500 \mathrm{~m}^{2} / \mathrm{g}$ but has been found to be in excess of $3,000 \mathrm{~m}^{2} / \mathrm{g}$ (Bansal et al., 2005). The surface area contains mostly micro pores with pore diameters smaller than $2 \mathrm{~nm}$. These favorable properties make activated carbon a popular adsorbent for many applications (Gomez et al., 2009). Ania et al., (2014) reported that sorption capacities were 0.86 and $1.781 \mathrm{mg} / \mathrm{g}$ for activated and non-activated coconut husk respectively. Non-activated coconut husk presented the highest adsorption capacities for the Cr (VI) ion. Also Daud et al, (2004) reported that $89 \%$ of copper ion removal with coconut husk as the adsorbent can be achieved at 120-minute contact time. Sun et al, (2006) reported that coconut husk can be effectively used to remove methylene blue from solution. Important functional groups responsible for ion uptake include $\mathrm{O}-\mathrm{H}, \mathrm{N}-\mathrm{H}, \mathrm{C}-\mathrm{O}$ and $\mathrm{C}=\mathrm{O}$ groups (Sun et al., 2006). Due to the disposal of heavy metals such as Chromium, Lead, and Copper, the pollution of water resources has been an increasing worldwide concern for the last few decades. The quality of water supply is affected due to discharge of toxic metals into water sources and is a serious pollution problem. In the industrialized world, the use of chromium in industries like electroplating, textile, leather tanning, metallurgical metal finishing, photography, dye manufacturing, ink and pigments, power generation, and chemical manufacturing etc., is extensive and hence it is not uncommon for the aqueous effluents from such industrial plants to have high amounts of chromium. Advance technologies such as ion exchange, chemical precipitation, ultrafiltration, or electrochemical deposition have been used for removal of heavy metals in wastewater which do not seem to be economically feasible for such industries because of their relatively high costs. Therefore, there is a need to look into alternatives low-cost method, which is effective and economic, and can be used by such industries. Many methods have been used namely: membrane filtration, coagulation, adsorption, oxidation, ion exchange, and precipitation as reported in the literature, but few of them were accepted due to cost, low efficiency, and inapplicability to a wide variety of Pollutants. Hence, there exists a scope to try locally available, low cost adsorbents for treatment of effluents containing heavy metals. Adsorbents from local origin: coconut husk was selected as adsorbent. The isotherm data for this adsorbent were fitted into the Langmuir and Freundlich models and kinetic parameters were determined. The results indicate that the locally available and freely abundant agriculture waste coconut husk can be treated as economically viable for the removal of metal ions from textile effluent. 


\section{Materials and Methods}

\subsection{Adsorbent Preparation}

The coconut used in this work was gotten directly from a coconut tree in kabala west Kaduna. The coconut husk was removed by separating the outer covering shell from the main coconut shell and soaked in distilled water for one hour. The wet coconut husk was sun dried for 24 hour and latter dried in a dryer at $45^{\circ} \mathrm{C}$ for one hours to form partial carbonized husk carbon (PCHC). Finally, the dried PCHC was oven-dried overnight at $45^{\circ} \mathrm{C}$ and crushed into $0.6 \mu \mathrm{m}$ particle size to formed $\mathrm{CHC}$. The $\mathrm{CHC}$ was then packed into a desiccator for utilization.

\subsection{Preparation of Cationic Solution}

The stock solution of $1000 \mathrm{ppm}$ Cr (VI) was prepared by dissolving 19.4 g quantity of Potassium dichromate $\left(\mathrm{K}_{2} \mathrm{Cr}_{2} \mathrm{O}_{7}\right)$ in $500 \mathrm{ml}$ de-ionized water. Working solution of $\mathrm{Cr}$ (VI) standard was prepared by diluting the appropriate quantity of the above stock solution. Stock solution of lead $\left(\mathrm{Pb}^{+2}\right)$ and cupper $\left(\mathrm{Cu}^{+2}\right)$ solutions were prepared by adopting same methods from copper and lead sulphate powders.

\subsection{Sorption Studies}

\subsubsection{Batch Experiment and Adsorption Isotherms}

Batch experiment were carried out to determine the adsorption isotherms of metal ions onto the adsorbent in a $500 \mathrm{ml}$ adsorption glass flask. The flask was shaken at a constant rate to allowe sufficient time for equilibrium. The $\mathrm{pH}$ of the solution in the flask was measured with a Graffin$\mathrm{pH}$ meter. The flask was kept closed to avoid the fluctuation of $\mathrm{pH}$. The effects of contact time, $\mathrm{pH}$, adsorbent dosage, and temperature were observed. The amount of metal adsorbed per unit mass is calculated using equation 1 :

$$
Q_{e}=\frac{\left(C_{i}-C_{e}\right)}{m}
$$

Where

$\mathrm{C}_{\mathrm{i}}$ and $\mathrm{C}_{\mathrm{e}}$ are the initial and equilibrium concentration $(\mathrm{mg} / \mathrm{L}), \mathrm{m}$ is the mass of the adsorbent $(\mathrm{g})$. Percent metal ion removal (\%MR) was calculated using equation 2 :

$$
\% M R=\frac{\left(C_{i}-C_{e}\right)}{C_{i}} \times 100
$$

\section{Results and Discussions}

\subsection{Effect of Adsorbent Dose on Adsorption}

The effect of adsorbent dose on the adsorption of the heavy metals onto $\mathrm{CHC}$ was investigated. Metals adsorption capacity of the $\mathrm{CHC}$ was increased with increase in adsorbent dose as evidently shown in Table 1 and Figure 1 below. This revealed that the adsorption sites remain unsaturated 
during the adsorption process and the number of sites available for adsorption increases by increasing the adsorbent dose as reported by Hammed et al., (2007). This also revealed that the Percent metal ion removal $(\% \mathrm{MR})$ increases as the adsorbent dose increases.

Table 1: Varying adsorbent dose

\begin{tabular}{|l|l|l|l|l|l|l|l|l|}
\hline \multicolumn{2}{|l|}{ Chromium (Cr) } & \multicolumn{2}{l|}{ Lead (Pb) } & \multicolumn{2}{l|}{ Cupper } \\
\hline Time (min) & $\begin{array}{l}\text { Dose } \\
(\mathbf{g})\end{array}$ & $\begin{array}{l}\mathbf{Q}_{\mathbf{e}} \\
(\mathbf{m g} / \mathbf{L})\end{array}$ & Time (min) & Dose $(\mathbf{g})$ & $\begin{array}{l}\mathbf{Q}_{\mathbf{e}} \\
(\mathbf{m g} / \mathbf{L})\end{array}$ & Time (min) & $\begin{array}{l}\text { Dose } \\
(\mathbf{g})\end{array}$ & $\begin{array}{l}\mathbf{Q}_{\mathbf{e}} \\
(\mathbf{m g} / \mathbf{L})\end{array}$ \\
\hline 60 & 20 & 34.5 & 60 & 20 & 29.32 & 60 & 20 & 23.40 \\
\hline 60 & 30 & 59.17 & 60 & 30 & 60.50 & 60 & 30 & 60.20 \\
\hline 60 & 40 & 126.60 & 60 & 40 & 112.91 & 60 & 40 & 100.10 \\
\hline 60 & 100 & 187.10 & 60 & 100 & 171.70 & 60 & 100 & 180.10 \\
\hline
\end{tabular}

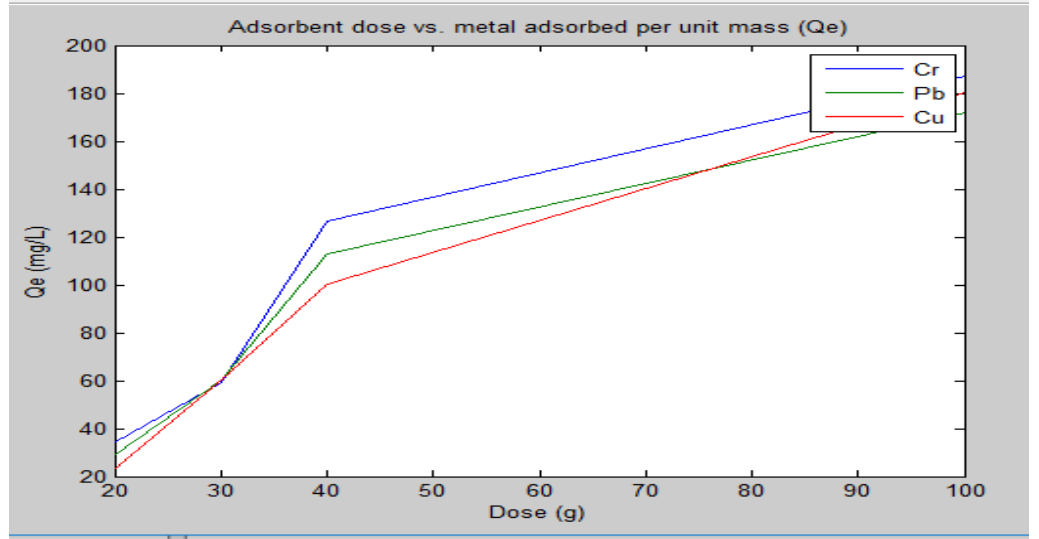

Figure 1: Effect of varying adsorbent dose on adsorption of metal

\subsection{Effect of Contact Time}

The effect of contact time on the adsorption of metal onto $\mathrm{CHC}$ was investigated. Figure 2 shows the percent metal ion removal with respect to contact time. Contact time is one of the most effective factors in batch adsorption process (Hanit et al., 2016). Adsorption rate rapidly increases initially, and the optimal removal was reached within 70 minute.

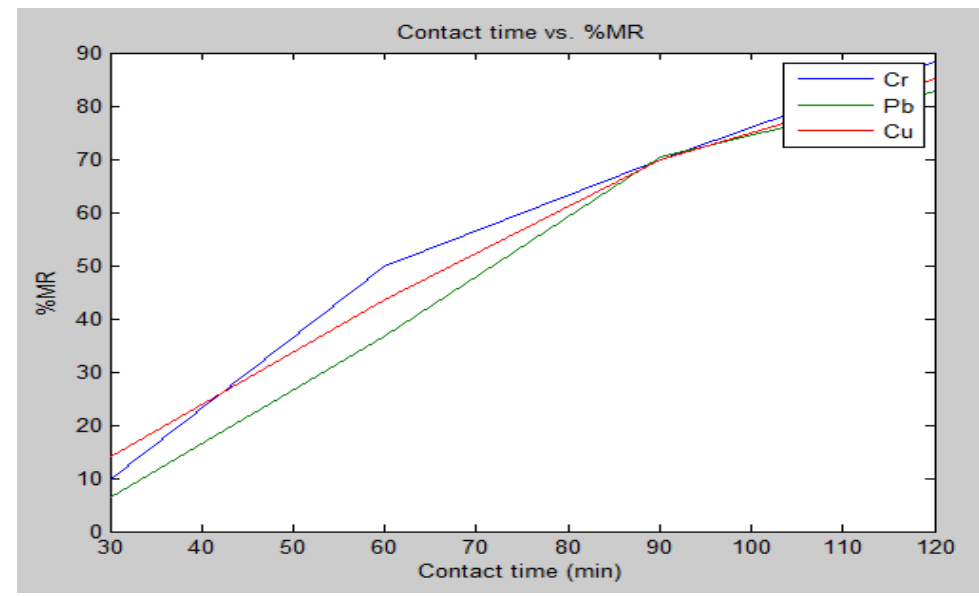

Figure 2: Effect of contact time on adsorption of metal 


\subsection{Effect of Temperature on Adsorption}

Effect of temperature on adsorption of the heavy metal onto CHC was investigated by conducting different sets of experiment at different temperature as shown in Table 2 below. It was observed that absorption of metal slightly increases with increase in temperature.

Table 2: Effect of temperature on uptake of $\mathrm{Cr}(\mathrm{VI})$

\begin{tabular}{|l|l|l|l|l|l|l|}
\hline Runs & Temperature $\left({ }^{\mathbf{c}} \mathbf{c}\right)$ & Dosage(g) & Time(min) & $\begin{array}{c}\text { Initial } \\
\text { conc(M) }\end{array}$ & $\begin{array}{c}\text { Final } \\
\text { conc(M) }\end{array}$ & $\begin{array}{c}\text { \% of } \\
\text { Adsorption }\end{array}$ \\
\hline $\mathbf{1}$ & 40 & 5 & 15 & 0.1 & 0.0112 & 88.9 \\
\hline $\mathbf{2}$ & 50 & 5 & 15 & 0.1 & 0.0125 & 87.5 \\
\hline $\mathbf{3}$ & 60 & 5 & 15 & 0.1 & 0.0142 & 85.8 \\
\hline $\mathbf{4}$ & 70 & 5 & 15 & 0.1 & 0.0159 & 84.1 \\
\hline $\mathbf{5}$ & 80 & 5 & 15 & 0.1 & 0.0180 & 82.0 \\
\hline
\end{tabular}

\subsection{Effect of pH on Adsorption}

During this study, results revealed that removal of metal ions was strongly depend on the $\mathrm{pH}$ of the solution. The effect of $\mathrm{pH}$ on adsorption of metal ions onto $\mathrm{CHC}$ was studied at $\mathrm{pH} 2-10$, and the maximum removal was found to be at $\mathrm{pH}$ 6.9. Further increase in $\mathrm{pH}$ causes decrease in the adsorption rate.

\subsection{Adsorption Isotherm}

Adsorption process is usually described through isotherms which is a functions that connect the amount of adsorbate on the adsorbent and the equilibrium concentration of the adsorbate. The distribution of metal ion on the adsorbent can be described by several isotherm models such as Langmuir and Freundlich. The Langmuir isotherm model assumes monolayer adsorption onto a surface containing a finite number of adsorption sites of uniform strategies with no transmigration of adsorbate in the plane surface (Mulu, 2013). Once the empty sites are filled, no further sorption can take place at the site. The isotherm is represented by

$$
\frac{C_{e}}{q_{e}}=\frac{1}{b q_{\max }}+\frac{C_{e}}{q_{\max }}
$$

The linear plot of specific adsorption $\left(\mathrm{C}_{\mathrm{e}} / \mathrm{q}_{\mathrm{e}}\right)$ against the equilibrium concentration $\mathrm{C}_{\mathrm{e}}$ as shown in Figure 3 shows that the adsorption data fitted well with Langmuir model. The constant $\mathrm{b}$ and $\mathrm{q}_{\max }$ relate to the energy of adsorption and maximum adsorption capacity, and their values are obtained from the slope and interception of the plot. 

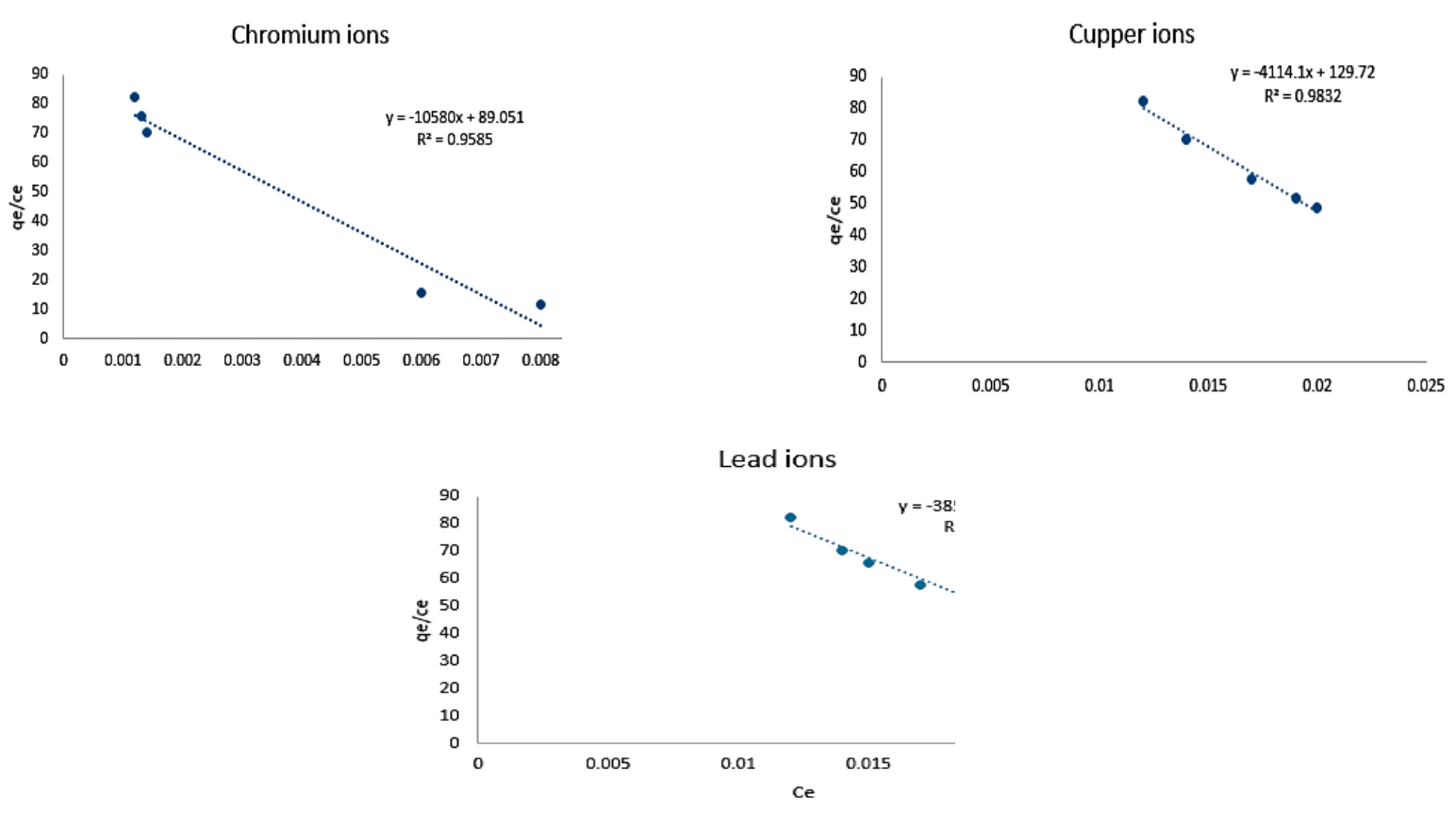

Figure 3: Langmuir isotherms $\mathrm{C}_{\mathrm{e}} / \mathrm{qe}$ vs $\mathrm{C}_{\mathrm{e}}$

The Freundlich isotherm model is an empirical model, where $\mathrm{q}_{\mathrm{e}}$ represents the amount adsorbed per amount of adsorbent at the equilibrium. The model is shown below:

$$
q_{e}=K_{f} C_{e}^{1 / n}
$$

Where $\mathrm{q}_{\mathrm{e}}$ represents the amount adsorbed per amount of adsorbent at the equilibrium $(\mathrm{mg} / \mathrm{g}), \mathrm{C}_{\mathrm{e}}$ represents the equilibrium concentration $(\mathrm{mg} / \mathrm{L})$, and $\mathrm{K}_{\mathrm{f}}$ and $\mathrm{n}$ are parameters that depend on the adsorbate and adsorbent. They are Freundlich constants which correspond to adsorption capacity and adsorption intensity respectively. Equation 4 can be linearized to obtained equation 5 and the temperature dependent constant $\mathrm{K}_{\mathrm{f}}$ and $1 / \mathrm{n}$ can be found by linear regression;

$$
\ln q_{e}=\ln K_{f}-\frac{1}{n} \ln C_{e}
$$

The Freundlich equilibrium constant were determined from the plot of $\ln q_{\mathrm{e}}$ versus $\ln \mathrm{C}_{\mathrm{e}}$ on the basis of the linear form of Freundlich equation. The $n$ value indicates the degree of nonlinearity between solution concentration and adsorption. If $\mathrm{n}=1$, then adsorption is linear, if $\mathrm{n}<1$, then adsorption is a chemical process; if $n>1$, then adsorption is a physical process (Mulu, 2013). In this study, the value of $n$ was found to be less than 1 which indicated that the adsorption of the metal ions onto the CHC is chemical sorption. The situation $n>1$ is most common and may be due to a distribution of surface sites or any factor that cause a decrease in adsorbent-adsorbate interaction with increasing surface density (Reed and Matsumoto, 1993). The value of $n$ within the range of 1 - 10 represent good adsorption (McKay et al.;1980; Ozer and Pirincci, 2006). 


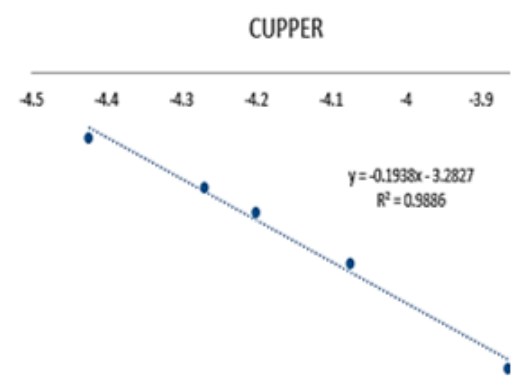

unce

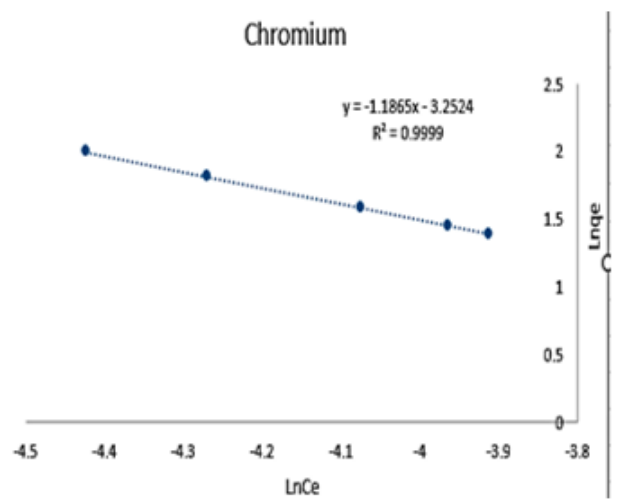

Figure 4: Freundlich isotherms $\mathrm{Inq}_{\mathrm{e}} \mathrm{vs} \mathrm{InC}_{\mathrm{e}}$

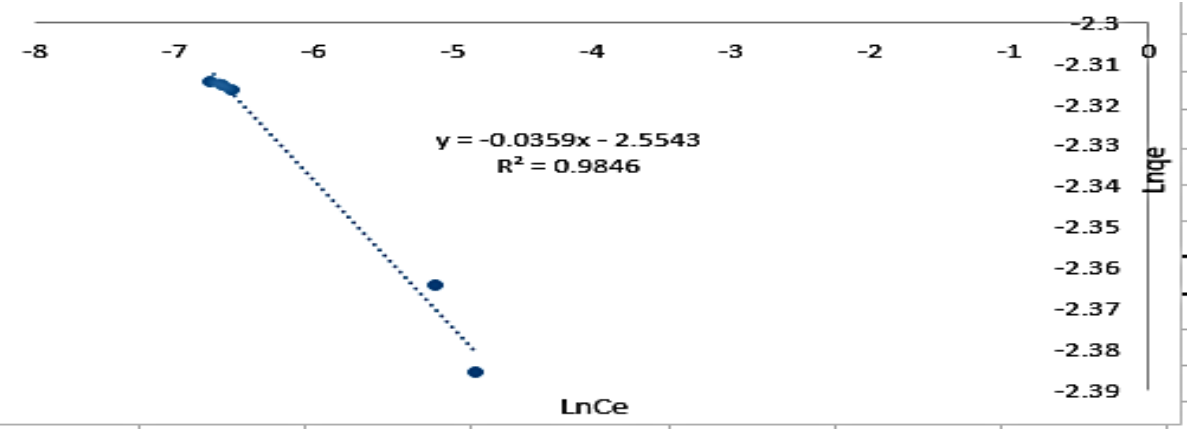

Figure 5: Freundlich isotherms $\mathrm{Inq}_{\mathrm{e}} \mathrm{vs} \mathrm{InC}_{\mathrm{e}}$ for lead

Table 3: Isotherm and kinematic properties of Chromium ions adsorption onto CHC

\begin{tabular}{|l|l|l|l|l|l|l|l|l|l|}
\hline $\mathbf{C}_{\mathbf{e}}$ & $\mathbf{q}_{\mathbf{e}}$ & $\mathbf{q}_{\mathbf{e}} / \mathbf{C}_{\mathbf{e}}$ & $\mathbf{I n C}_{\mathbf{e}}$ & $\mathbf{I n q}_{\mathbf{e}}$ & $\mathbf{1} / \mathbf{n}$ & $\mathbf{n}$ & $\mathbf{K}_{\mathbf{f}}$ & $\mathbf{b}$ & $\mathbf{q}_{\mathbf{m a x}}$ \\
\hline 0.012 & 0.088 & 7.3333 & -4.4228 & -1.9924 & 3.2524 & 0.307465 & 0.3052879 & 89.051 & 10580 \\
\hline 0.014 & 0.086 & 6.1428 & -4.2687 & -1.8152 & & & & & \\
\hline 0.017 & 0.083 & 4.8823 & -4.0745 & -1.5856 & & & & & \\
\hline 0.019 & 0.081 & 4.2631 & -3.9633 & -1.4500 & & & & & \\
\hline 0.020 & 0.080 & 4.0000 & -3.9120 & -1.3862 & & & & & \\
\hline
\end{tabular}

Table 4: Isotherm and kinematic properties of Lead ions adsorption onto CHC

\begin{tabular}{|c|c|l|c|l|l|l|l|l|l|}
\hline $\mathbf{C}_{\mathbf{e}}$ & $\mathbf{q}_{\mathbf{e}}$ & $\mathbf{q}_{\mathbf{e}} / \mathbf{c}_{\mathbf{e}}$ & $\mathbf{I n C}_{\mathbf{e}}$ & $\mathbf{I n q} \mathbf{q}_{\mathbf{e}}$ & $\mathbf{1} / \mathbf{n}$ & $\mathbf{n}$ & $\mathbf{K}_{\mathbf{f}}$ & $\mathbf{b}$ & $\mathbf{q}_{\max }$ \\
\hline 0.0060 & 0.0940 & 15.6666 & -5.1160 & -2.3644 & 2.5543 & 0.391497 & 0.96473676 & 125.47 & 3853.9 \\
\hline 0.0080 & 0.0920 & 11.5000 & -4.8283 & -2.3859 & & & & & \\
\hline 0.0012 & 0.0988 & 82.3333 & -6.7254 & -2.3146 & & & & & \\
\hline 0.0014 & 0.0986 & 70.4285 & -6.5712 & -2.3166 & & & & & \\
\hline 0.0013 & 0.0987 & 75.9230 & -6.6453 & -2.3156 & & & & & \\
\hline
\end{tabular}

Table 5: Isotherm and kinematic properties of Cupper ions adsorption onto $\mathrm{CHC}$

\begin{tabular}{|c|c|c|c|c|c|c|c|c|c|}
\hline$C_{e}$ & $q_{e}$ & $\mathrm{q}_{\mathrm{e}} / \mathrm{C}_{\mathrm{e}}$ & $\mathrm{InC}_{\mathrm{e}}$ & Inq $_{e}$ & $1 / n$ & $\mathrm{n}$ & $\mathbf{K}_{\mathbf{f}}$ & $\mathbf{b}$ & $\mathbf{q}_{\max }$ \\
\hline 0.014 & 0.086 & 6.1428 & -4.2687 & -2.4534 & 3.2827 & 0.304627 & 0.82382265 & 129.72 & 4114.1 \\
\hline 0.017 & 0.083 & 4.8823 & -4.0745 & -2.4889 & & & & & \\
\hline 0.015 & 0.085 & 5.6666 & -4.1997 & -2.4651 & & & & & \\
\hline
\end{tabular}




\begin{tabular}{|l|l|l|l|l|l|l|l|l|l|}
\hline 0.012 & 0.088 & 7.3333 & -4.4228 & -2.4304 & & & & & \\
\hline 0.021 & 0.079 & 3.7619 & -3.8632 & -2.5383 & & & & & \\
\hline
\end{tabular}

\section{Conclusions and Recommendations}

Coconut husk which is environmentally friendly, locally available agro-waste is a good adsorbent for the adsorption of heavy metal ions. Results from this study indicated that adsorption of metal ions onto coconut husk increases with the amount of adsorbent, contact time, temperature, and $\mathrm{pH}$. The adsorption isotherm could well be fitted by both Langmuir and Freundlich based on r-square values obtained from both models. $\mathrm{R}_{\mathrm{I}}$ (equilibrium parameter) value in the present investigation was less than one which indicate that the adsorption of the heavy metals ions on the CHC is favorable. The value of $\mathrm{n}$ which indicates the degree of nonlinearity between solution concentration and adsorption is less than one $(n<1)$, indicating that the adsorption of metal ions onto coconut husk is chemical adsorption which is a drawback for the use of CHC industrially because it cannot be reusable or renewable.

\section{References}

[1] Abrowski, A. D, (2005). Adsorption - from theory to practice, Adv. Colloid Interface Sci, pg 135 224.

[2] Ania, C.O., Parra, J.B., Menendez, J.A., and Pis, J.J., (2005). Effect of microwave and Conventional regeneration on the microporous and mesoporous network and on the adsorptive capacity of activated carbons; Journal of Hazardous Materials, vol 14, pg 7 - 15.

[3] Bansal, R.C., Donnet, J.B., and Stoeckli, F., (2005), Active Carbon; Marcel Dekker Inc., New York.

[4] Daud, A.W., and Ali, S.W., (2004). Comparison on pore development of Activated carbon produced from palm shell and coconut shell; Journal of Environmental Science and Technology pg $63-69$.

[5] Gomez, Serrano. (2009), The development of an activated carbon from corn Cob and its use in the removal of Ochratoxin A from red wine. Journal of Hazardous Materials, vol 130, pg 298 - 303.

[6] Hammed, B. H., Din, A. T., Ahmad, A. I. (2007), Adsorption of methylene blue onto bamboobased activated carbon: kinetic and equilibrium studies, Journal of Hazardous Materials, vol 141, pp. $819-825$.

[7] McKay, G., Otterburn, M. S., Sweeney, A. G., (1980). The removal of colour from effluent using various adsorbents. Water Research, vol, 14, pg. $15-20$.

[8] Mulu, B. D., (2013), Batch Sorption Experiments: Langmuir and Freundlich Isotherm Studies for the Adsorption of Textile Metal Ions onto Teff Straw (Eragrostis tef) Agricultural Waste, Journal of Thermodynamics, vol. A, pp $6-11$.

[9] Reed, B. E., Matsumoto, (1993). Modeling cadmium adsorption by activated carbon using the Langmuir and Freundlich isotherm expressions. Separation Science and Technology, vol. 28, pg. $13-14$.

[10] Sun, Y., Zhang, J.P., Yang, G., and Li, Z.H., (2006), Removal of pollutants with Activated Carbon produced from $\mathrm{K}_{2} \mathrm{CO}_{3}$ activation of lignin from reed black Liquors, Journal of Environmental Science and Technology, vol 2, pg 429-435.

[11] Ozer, A., Pirincci, H. B, (2006). The adsorption of Cd (II) ions on sulphuric acid-treated wheat bran. Journal of Hazardous Materials, vol 137, pg. 849 - 855.

*Corresponding author.

E-mail address: musa@ kadunapolytechnic.edu.ng 